\section{IN BRIEFS}

\section{CHRONIC PAIN}

In a randomized controlled trial that involved 123 individuals with persistent arm pain, real and sham acupuncture both improved arm pain scores after 8 treatments over 4 weeks. Patients given genuine acupuncture experienced more mild adverse effects than those who underwent sham procedures.

Original article Goldman RH et al. (2008) Acupuncture for treatment of persistent arm pain due to repetitive use: a randomized controlled clinical trial. Clin J Pain 24: 211-218

\section{SYSTEMIC LUPUS ERYTHEMATOSUS}

In a study that analyzed single-photonemission CT brain scans by the stereotactic surface projection technique, patients with systemic lupus erythematosus $(n=37)$ had reduced perfusion of the watershed areas of the frontal lobes compared with controls $(n=19)$. The severity of reduced perfusion correlated with the severity of cognitive dysfunction experienced by the patient.

Original article Driver CB et al. (2008) Clinical validation of the watershed sign as a marker for neuropsychiatric systemic lupus erythematosus. Arthritis Rheum 59: 332-337

\section{SJÖGREN'S SYNDROME}

In a small, double-blind, placebo-controlled, randomized trial of rituximab, 17 patients with primary Sjögren's syndrome were assessed to determine the effects of treatment on fatigue, symptoms, quality of life and immunological parameters of disease. Rituximab-treated patients had significantly reduced fatigue $(P<0.001)$ and significantly improved social functioning $(P=0.01)$ compared with placebo-treated patients.

Original article Dass S et al. (2008) Reduction of fatigue in Sjögren's syndrome with rituximab: results of a randomised, double-blind, placebo controlled pilot study. Ann Rheum Dis [doi.10.1136/ard.2007.083865]

\section{RHEUMATOID ARTHRITIS}

Olech et al. studied 44 patients to determine the optimal joint combination for detecting erosions by extremity MRI in patients with early rheumatoid arthritis. The authors concluded that extremity MRI scans of both hands can be used to screen patients, and that imaging one hand is sufficient to monitor the progression of erosions.

Original article Olech E et al. (2008) Using extremity magnetic resonance imaging to assess and monitor early rheumatoid arthritis: the optimal joint combination to be scanned in clinical practice. J Rheumatol 35: 580-583

\section{OSTEOARTHRITIS}

Intra-articular injections of hylan G-F 20 were administered to 32 patients with mildto-moderate knee osteoarthritis to identify predictors of a clinical response. High baseline concentrations of hyaluronic acid in synovial fluid were associated with good clinical responses, and 15 patients achieved $\mathrm{a} \geq 50 \%$ improvement in pain or function. Baseline clinical and radiographic measures did not correlate with clinical responses to intraarticular hylan G-F 20 injections in this cohort.

Original article Anandacoomarasamy A et al. (2008) Predictors of clinical response to intraarticular hylan injections - a prospective study using synovial fluid measures, clinical outcomes, and magnetic resonance imaging. J Rheumatol 35: 685-690

\section{SCLERODERMA}

Nail-fold videocapillaroscopy can be used to monitor microvascular remodeling in patients with severe, diffuse, cutaneous systemic sclerosis. Patients who received autologous stem-cell transplants $(n=6)$ showed signs of such remodeling, whereas patients who received cyclophosphamide-based treatment $(n=10)$ did not.

Original article Miniati I et al. (2008) Autologous stem cell transplantation improves microcirculation in systemic sclerosis. Ann Rheum Dis [doi.10.1136/ard.2007.082495] 